\title{
The Influence of Industrial Transfer on Regional Total Factor Productivity and Its Path Analysis
}

\author{
Cangcang JIA \\ School of Economics and Management, Chongqing Normal University \\ Chongqing 401331, China
}

\begin{abstract}
Based on the industry assets and input-output data of labor-intensive industries in China from 1997 to 2016, this paper empirically tests the impact of industrial transfer on regional total factor productivity and its impact path through panel VAR and mediation effect models. The study found that: (1) China's labor-intensive industry transfer significantly affects regional total factor productivity, in which industrial transfer increases the total factor productivity of industrial transfer and reduces the total factor productivity of industrial support; (2) industrial transfer significantly affectes the total factor productivity by its impact on human capital. Finally, the corresponding countermeasures and suggestions are put forward.
\end{abstract}

Keywords-Industrial transfer; Total factor productivity; Panel VAR; Mediation effect model

\section{INTRODUCTION}

Since the reform and opening up, China has grasped the opportunities of global industrial transfer and made full use of its comparative advantages such as rich labor resources to undertake a large number of international industrial transfers. Especially, the eastern region has become the main transfer-in place of international industrial transfer with its regional advantages. In recent years, the price of land, labor and other factors in the eastern region of China has been rising, and the household registration system, etc., has restrictions on the cross-regional transfer of labor, labor and resource-intensive industries began to transfer to the central and western regions. To some extent, capital transfer promotes the economic scale of the central and western regions, but this kind of transfer may bring the loss of efficiency due to the influence of geographical location. Although the central and western regions have comparative advantages in terms of capital prices, there are still gaps in technology, talent and innovation ability compared with the eastern regions. This involves a deeper issue, that is, the quality and efficiency of economic development, while the quality and efficiency of regional development is often expressed as total factor productivity [1]. Therefore, exploring the relationship between industrial transfer and total factor productivity is of great significance to increase the level of regional development and promote regional coordinated development.

\section{LITERATURE REVIEW}

Industrial transfer is the process of dynamic adjustment of industrial structure. The basic path is to change the regional distribution of newly-increased industrial capital to optimize the allocation of resources. From the perspective of enterprises, there are two forms of industrial transfer: "off-site investment" and "factory transfer"; From the macro-level, industrial transfer mainly refers to the change of the share of new industrial capital in the whole region. This paper mainly studies the industrial transfer in China based at the macro-level. Due to the difference of regional economic environment, industrial transfer may lead to resource allocation efficiency changes, which is an important aspect of total factor productivity changes [2]. Resource allocation efficiency is related to technology spillover, industrial agglomeration and structural optimization. Most of the existing studies examine the relationship between industrial transfer and the above three from a static perspective, but conclusions are different. Caves (1974), Wolff (1994) et al. pointed out that the spillover effect caused by the transnational flow of international industry capital can improve the industry productivity of the transfer-in place [3] [4] through the research on the international transfer of different industries; Gongwei ZHANG et al. (2013) found that technology spillover and positive externalities of industrial agglomeration caused by FDI have a significant influence on the total factor growth rate by studying the relationship between FDI, industrial agglomeration and total factor productivity [5]; Jianyong FAN et al (2014) found that industrial agglomeration mainly improves total factor productivity by improving technical efficiency through the research of electronic equipment industry agglomeration [6]; Yonghong MA et al. (2015) examined the impact of industrial transfer on the innovation capability of enterprises in underdeveloped regions, pointing out that industrial transfer has promoted the innovation capability of enterprises through the path of linkage embeddedness and adaptive competition [7] Ziyuan XIE et al. (2017) analyzed the relationship between industrial agglomeration and enterprise innovation efficiency, and found that the relationship between industrial agglomeration and enterprise innovation efficiency is inverted U-shaped relationship [8]; Although the above research does not directly discuss the relationship between industrial transfer and total factor productivity, it implies that industrial transfer promotes the promotion of total factor productivity. However, some scholars believe that the policy-driven industrial transfer will bring too much national capital, which will crowd out the existing industries. At the same time, it will destroy the 
existing development path to a certain extent, which will have a negative impact on total factor productivity; Moreover, with the strengthening of environmental regulation in recent years, many highly polluting industries have been forced to transfer, which increases the cost of environmental governance in transfer-in area and has a great impact on total factor productivity. Haddad et al. (1993) used the cross-sectional data of Moroccan manufacturing enterprises to find that higher level of international industrial transfer does not bring productivity growth and positive technology spillover effect of domestic enterprises [9]; Aitken et al. (1999) used panel data of Venezuelan factories to find that international industrial transfer has a negative impact on the productivity of firms in transfer-in area [10]; Through research on capital transfer and resource allocation efficiency, Ming LU et al (2014) found that capital transfer reduced the degree of economic agglomeration, and low factor prices in the central and western regions made inefficient enterprises survive, which reduced the efficiency of resource allocation; Xiusheng ZHANG et al. (2017) used the data of industrial transfer of prefecture-level cities in China to find that, industrial transfer index and total factor productivity have significant negative correlation. The above studies discussed and proved the negative effect of industrial transfer on total factor productivity more directly.

The difference between the two conclusions may be due to the changes in the economic environment of the subjects. At the beginning of reform and opening up, it was essentially the transformation from the planned economy to market economy and from the agricultural economy to industrial economy. In view of the essential difference between the two transformation modes in promoting the efficiency of resource allocation, the initial undertaking of international industrial transfer promoted the double promotion of economic scale and economic efficiency in the eastern region. With the deepening of reform and opening up, at present, most regions of China have basically entered the middle stage of industrialization. Restricted by the eastern factor cost, environmental regulation and other factors, the transfer of individual industries to the central and western regions may be motivated by the lower factor prices in the central and western regions so that the less efficient enterprises can survive (Ming LU, 2014). At this time, although the industrial transfer promotes the economic scale of the industrial transfer-in area, it may reduce its factor productivity. Based on the data of industry capital and input-output from 1997 to 2016, this paper uses panel VAR and Mediating Effect Model to empirically analyze the relationship between industrial transfer and total factor productivity and its influence path.

\section{THEORETICAL FRAMEWORK}

According to New Economic Geography, location differences lead to the imbalance of regional economic development, and industrial transfer also comes from the comparative advantage of interregional factor endowment. According to the practical experience of our country, in the early stage of reform and opening up, the eastern coastal area undertook a large number of international industrial transfers by making use of its rich resource endowment and location advantages. At the same time, China began to gather talents and capital to the eastern area, which greatly improved the total factor productivity of the eastern area. The central and western regions are rich in natural resources, but due to the location factors and brain drain, the economic development is relatively backward. At present, China has entered the middle and late industrialization period. With the deep adjustment of industrial division of labor, the pace of industrial transformation and upgrading in the eastern region has been accelerated. The rising price of land and labor, as well as the strengthening of environmental regulations, has led to a sharp increase in the production costs of many inefficient enterprises, which are mainly concentrated in labor-intensive, resource-intensive, high-energy-consuming and high-pollution industries; However, the central and western regions are rich in resources, low in factor cost and high in market potential, which impels these industries to transfer to the central and western regions.

Does industrial transfer improve regional resource allocation efficiency? Since 1978, China's industrial transfer has gone through two stages. The first stage is that the eastern region undertook the international industrial transfer in the initial stage of reform and opening up. The second stage is about the industrial transfer from the eastern region to the central and western regions in recent years. The results show that the industrial transfer in the first stage has indeed promoted the production efficiency and economic scale in the eastern region of China. However, this conclusion cannot be simply applied to the second stage, because the economic environment has undergone tremendous changes in these two stages. At initial stage of reform and opening up, China was facing the transition from planned economy to market economy, and the eastern region was also experiencing the transition from the agricultural economy to industrial economy. At this time, the improvement of production efficiency in the eastern region may be due to the simultaneous improvement of economic scale and production efficiency by correcting the loss of resource allocation efficiency caused by institutional distortion. In recent years, the industry transfer has been mainly achieved by administrative intervention to allow the industrial capital cross-regional allocation, thus affecting the efficiency of regional resource allocation. The change of resource allocation efficiency may be related to the direction of industrial transfer. As the limited resources are biased to the industrial transfer in area, for the industrial transfer-out area, the limited resources will lead to the factor price rise, which will crowd out the inefficient enterprises, and at the same time will make the existing resources flow to the departments with higher productivity. Lower factor prices are likely to keep the newly-transferred-in inefficient enterprises survive in transfer-in area.

The change of total factor productivity mainly depends on the level of education and the efficiency of resource allocation. When the level of education is taken as an exogenous variable, the efficiency of resource allocation is equivalent to the total factor productivity. Based on the above theoretical analysis, this paper puts forward the research hypothesis: Industrial transfer can promote the total factor productivity of transfer-out area and inhibit the total factor productivity of transfer-in land. 


\section{DATA AND MODELS}

\section{A. Measurement of Industrial Transfer}

Industrial transfer is a dynamic change in the spatial distribution of industrial capital. Using the method of Fanbin Kong et al. (2017) [11], fixed asset investment transfer index (FAI) is used as a proxy variable of industrial transfer. According to the priority industries mentioned in the State

$$
F A I_{\mathrm{t}+1}=\left(F A I_{\mathrm{ij}_{\mathrm{t}+1}}-F A I_{\mathrm{ij}_{\mathrm{t}}}\right) / F A I_{\mathrm{ij}_{\mathrm{t}}}-\left(F A I_{\mathrm{j}_{\mathrm{t}+1}}-F A I_{\mathrm{j}_{\mathrm{t}}}\right) / F A I_{\mathrm{j}_{\mathrm{t}}}
$$

Among them, $\mathrm{i}$ province $\mathrm{j}$ industry $\mathrm{t}$ period fixed asset investment, $\mathrm{j}$ industry $\mathrm{t}$ period fixed asset investment, $\mathrm{i}$ province $t+1$ period industrial transfer index. If the FAI is negative, it will indicate the place where the industry is transferred out, and vice versa.

\section{B. Measurement of Total Factor Productivity}

Some scholars use labor productivity, wages and others to measure production efficiency (Liangwen CHEN [12], 2008), but in China's labor-intensive, resource-based manufacturing industry structure, labor productivity and wages may produce an underestimated efficiency estimate. Therefore, total factor productivity (TFP) is chosen to measure production efficiency and DEA-Malmquist index method is used to calculate TFP. The output variable is GDP, and the input variable is labor (employed population over the years) and capital (fixed asset investment over the years).

\section{Measurement Models}

(1) The influence of industrial transfer on total factor productivity. In order to verify whether there is a two-way causal relationship between industrial transfer and total factor productivity, panel VAR model is used to test. The model is as follows:

$$
T F P_{i t}=\alpha_{30}+\alpha_{31} T F P_{i t-1}+\alpha_{32} F A I_{\text {it }}+\alpha_{33} \text { Manpower }_{i t}+\alpha_{34} X_{i t}+\rho_{t}+\mu_{i}+\varepsilon_{i t}
$$

Among them, the control variable matrix, including economic development Economy, foreign capital OFDI, Infrastructure, industrial structure Industry and so on. $X_{\text {it }}$ Economy is expressed in terms of GDP per capita; Infrastructure is expressed in terms of per capita road area; Industry is expressed in terms of the tertiary sector's share in GDP. $\rho_{\mathrm{t}}$ Time effect; $\mu_{\mathrm{i}}$ Fixed effect. Manpower represents the mediating variable human capital.
Council's Guidance on Undertaking Industrial Transfer in Central and Western Regions, this paper selects five industries of mining, manufacturing, electricity and gas industry, architecture, transportation for research. The FAI is calculated as follows.

$$
\mathrm{y}_{\mathrm{it}}=\alpha_{i}+\beta_{0}+\sum \beta_{j} y_{i t-j}+\gamma_{i t}+\varepsilon_{i t}
$$

Among them, $\mathrm{y}_{i t}$ a vector containing two variables \{ TFP, FAI $\} \alpha_{\mathrm{i}}$ a fixed effect term of provincial difference, $\gamma_{\text {it }}$ a stochastic error term to overcome the specific impact $\varepsilon_{\text {it }}$ of cross-sectional correlation to bring structural changes.

(2) The influence path of industrial transfer on total factor productivity. According to the theoretical analysis, the change of total factor productivity mainly depends on the level of education. In order to verify whether industrial transfer affects regional total factor productivity by influencing education level, this paper adopts mediating effect analysis model to test the effect of industrial transfer on regional total factor productivity. According to the purpose of the study, the level of education is used as a mediator variable, and the model is as follows.

$$
\text { Manpower }_{i t}=\alpha_{20}+\alpha_{21} F A I_{i t}+\alpha_{22} X_{i t}+\rho_{t}+\mu_{i}+\varepsilon_{i t}
$$

\section{Data Sources and Descriptive Statistics}

The calculation method of variables and descriptive statistics of data are shown in Table 1. Based on the data of 31 provinces and autonomous regions in mainland China from 1997 to 2016. Data from China Statistical Yearbook and Guotai'an Database. Foreign investment is the logarithmic

\begin{tabular}{|c|c|c|c|c|c|c|}
\hline Variable & Calculation method & $\begin{array}{l}\text { Mean } \\
\text { value }\end{array}$ & $\begin{array}{l}\text { Varianc } \\
\mathrm{e}\end{array}$ & $\begin{array}{l}\text { Minimu } \\
\mathrm{m} \text { value }\end{array}$ & $\begin{array}{l}\text { Maxim } \\
\text { um } \\
\text { value }\end{array}$ & Sample size \\
\hline TFP & $\begin{array}{ll}\text { Total } & \text { factor } \\
\text { productivity } & \\
\end{array}$ & 1 & 0.0400 & 0.880 & 1.180 & 620 \\
\hline FAI & Industry transfer index & 0.0100 & 0.140 & -0.720 & 1.260 & 620 \\
\hline Industry & $\begin{array}{l}\text { Industrial Structure } \\
\text { Coefficient } \\
\text { Representation }\end{array}$ & 2.270 & 0.130 & 1.940 & 2.800 & 620 \\
\hline Economy & Per capita GDP & 9.770 & 0.900 & 7.700 & 11.68 & 620 \\
\hline Infrastructure & Road area per capita & 2.860 & 2.290 & 0.430 & 19.11 & 620 \\
\hline Manpower & $\begin{array}{l}\text { Proportion of college } \\
\text { students to permanent } \\
\text { resident population }\end{array}$ & 0.0200 & 0.0100 & 0 & 0.0800 & 620 \\
\hline
\end{tabular}
value; The US dollar is converted into Renminbi at the average exchange rate for the year.

TABLE I DESCRIPTIVE STATISTICS OF VARIABLES 


\begin{tabular}{|l|l|l|l|l|l|l|}
\hline \multicolumn{10}{|c|}{ Table I, cont } \\
\hline OFDI & $\begin{array}{l}\text { Foreign } \\
\text { investment in major } \\
\text { cities }\end{array}$ & $\begin{array}{l}\text { direct } \\
\text { major }\end{array}$ & 2.010 & -2.710 & 10.03 & 620 \\
\hline
\end{tabular}

\section{EMPIRICAL ANALYSIS}

\section{A. Impact of Industrial Transfer on Total Factor Productivity}

Determining the order of lag. The AIC, HQIC and SBIC methods are widely used to determine the lag order of PVAR model in the existing literatures, which are based on the ratio of the residual sum of squares to the number of parameters obtained from the estimation of each order model, and to determine the lag order according to the minimum value. The results are shown in Table 2.

TABLE II AIC, HQIC, SBIC RESULTS

\begin{tabular}{|l|l|l|c|}
\hline lag & AIC & HQIC & SBIC \\
\hline 1 & $-5.3752 *$ & $-3.51239 *$ & $-4.61697 *$ \\
\hline 2 & -5.33965 & -3.35494 & -4.53367 \\
\hline 3 & -5.28755 & -3.16868 & -4.42926 \\
\hline
\end{tabular}

The first-order lag model is determined according to the three information criteria in Table 2. The concrete form of the first-order panel VAR model is as follows:

$$
\mathrm{y}_{i t}=\alpha_{i}+\beta_{0}+\beta_{1} y_{i t-1}+\gamma_{i t}+\varepsilon_{i t}
$$

Panel VAR estimation. TFP and FAI were used as explanatory variables, and their first-order lag terms were used as interpreted variables. The results are shown in Table 3. It was found that TFP was affected by its lag period 1 (0.500), indicating that TFP in the previous period had a $50 \%$ effect on TFP in the current period. Under the condition of keeping TFP unchanged, the TFP raised by human capital and technology accumulation in the previous period also has $50 \%$ effect on the current period, and this effect will continue to decline in the long run, so keeping TFP unchanged requires the continuous investment of human capital and technology accumulation. FAI has a negative effect on TFP, the coefficient of lag 1 period is-0.028, It can be found that the TFP of the current period is affected by the FAI of the previous period. If the previous period is for the industry transfer out, the TFP of the current period will increase by $2.8 \%$, otherwise it will decrease, which indicates that the factor productivity of the transfer out industry is often low, and the increase of resources and the decrease of human cost do not change the enterprise development mode from the "extensive" mode to the "intensive" mode, but reduce the resource utilization rate.

However, FAI is not affected by TFP lag period, indicating that the direction of industrial transfer in the current period is not affected by the factor productivity of the previous period. However, FAI is affected by its own lag period 1, and the coefficient is 0.247 , which shows that industrial transfer is easy to form a trend. As an industrial transfer-out area, for resource-intensive, human-intensive and high-pollution industries, it will continue to transfer out, while the industrial transfer-in place will continue to undertake the relevant industries.

TABLE III

PANEL VAR ESTIMATES

\begin{tabular}{|l|l|l|l|l|l|}
\hline \multirow{2}{*}{ Explained variable } & Explanatory variable & Factor & Standard error & T value & P Value \\
\hline \multirow{2}{*}{ TFP } & L. TFP & $0.499^{* * *}$ & 0.0454344 & 10.98 & 0.000 \\
\cline { 2 - 6 } & L. FAI & $-0.028^{* * *}$ & 0.0091162 & -3.11 & 0.002 \\
\hline \multirow{2}{*}{ FAI } & L. TFP & 0.054 & 0.2229069 & 0.24 & 0.807 \\
\cline { 2 - 6 } & L. FAI & $0.2468^{* * *}$ & 0.0447254 & 5.52 & 0.000 \\
\hline
\end{tabular}

Impulse response analysis after 1000 times of Monte-Carlo simulations, the pulse shock diagram between FAI and TFP was plotted (Figure 1). Figure. 1 shows that number of lag period of the impact effect on the horizontal axis, FAI or TFP on the vertical axis, and the middle line is the pulse line, with 95\% confidence intervals respectively. The first plot shows that the TFP will increase in the future period after a positive impact, but the magnitude of the increase is slowly decreasing; A second plot shows the response of TFP at the time of a positive impact given to FAI at current period. The impact exerted in the current period does not affect the current TFP, but from the first period, the impact is significantly negative, and in the second period, the impact is the largest, and the negative impact gradually decreases thereafter, which shows that the industrial transfer does have a negative impact on the total factor productivity of the industrial transfer-in area; The third plot shows the effect on the FAI after a positive impact given to TFP; The whole plot basically contains the horizontal axis, which can be considered to be zero in $95 \%$ confidence interval. This shows that the change of regional productivity will not cause the transfer of related industries. Most of the industrial transfer is driven by resources, human cost and policy reasons, and has nothing to do with regional productivity. The fourth plot shows the impact on FAI after a of the positive impact on it, and we can see that the positive impact is close to the coordinate axis quickly, basically zero after the second period, indicating that the cycle of industrial transfer is two years, and the impact of industrial transfer policy in the current period disappears after about two years. 


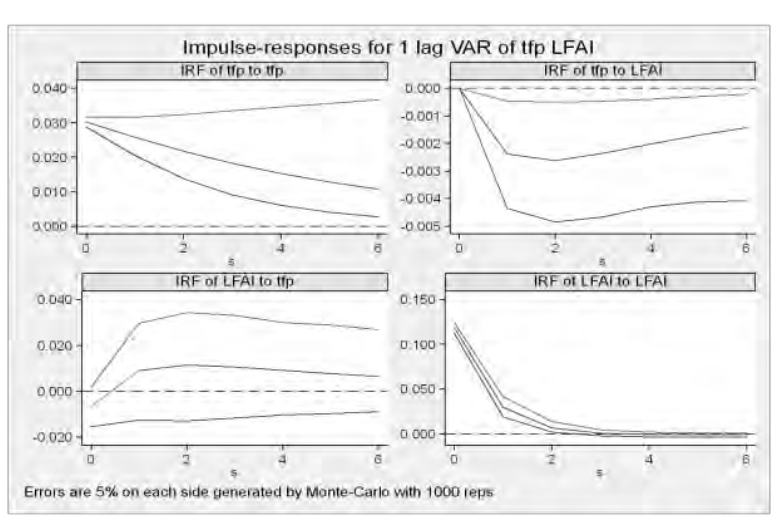

Fig. 1 Impulse Response Function Diagram

\section{B. The Influence Path of Industrial Transfer on Total Factor Productivity}

In order to test whether industrial transfer affects total factor productivity by changing human capital, the mediating effect of human capital is further analyzed, and the results are shown in Table 4. Models (1) and (2) are the regression of FAI to human capital in industrial transfer-in area and transfer-out area respectively. The FAI of the industrial transfer-out area is significantly negative at the $10 \%$ significance level, which indicates that the level of human capital of the industrial transfer-out area has been improved. But it is not significant for transfer-in area. The model (4) is the estimation results of the system GMM for the formula (8) based on the whole sample, and is used as the benchmark model for discussion. As a comparison, the estimation results of the difference GMM, the mixed OLS and the fixed effect model are given by the models (3), (5) and (6) respectively. According to estimated results, the coefficient of human capital is significantly positive, human capital can promote regional TFP, but it also proves that for the place where the industry is transferred out, human capital has a significant mediating effect, However, there is no mediating effect on the industrial transfer-in place, that is, industrial transfer affects the total factor productivity by improving the level of human capital of the industrial transfer-out area, and this path does not exist for the transfer-in area, which may be an important reason for the opposite effect of industrial transfer on the total factor productivity of the industrial transfer-in area and the industrial transfer-out area.

The first-order lag term of TFP is the explanatory variable of TFP, the coefficient is 0.452 and the $1 \%$ significance test is passed, showing that the regional TFP has some persistence, the main reason is that the influence of technology improvement on TFP decreases with time; FAI has a negative impact on TFP, the coefficient is- 0.03 and the $1 \%$ significance test is passed, showing that industrial transfer can indeed affect the regional TFP, and industrial transfer does have different impact on the place where the industry is transferred out and transferred in. From the control variables, Infrastructure, OFDI can promote the current TFP; The coefficient of Economy is significantly negative, indicating that the higher the level of economic development, the lower the TFP, which may be because the industries involved in this paper are labor-intensive, resource-intensive and heavily polluting industries. The higher the level of economic development, the higher the human and resource costs, and the stronger the environmental restrictions, which therefore has a negative impact on the TFP. Industry coefficient is not significant, indicating that the industrial transfer is not affected by the industrial structure of the transfer-out or transfer-in area

TABLE IV Regression Results of Mediating EFFeCt Model

\begin{tabular}{|c|c|c|c|c|c|c|}
\hline & \multicolumn{2}{|c|}{ Step2 : Human capital } & \multicolumn{4}{|l|}{ Step3: TFP } \\
\hline & (1) & (2) & (3) & (4) & (5) & (6) \\
\hline VARIABLES & Transfer-out area & Transfer-in area & $\begin{array}{l}\text { Differential } \\
\text { GMM }\end{array}$ & System GMM & Least Squares & Fixed effect \\
\hline \multirow[t]{2}{*}{ L. TFP } & & & $0.281^{* * *}$ & $0.452 * * *$ & $0.460 * * *$ & $0.349 * * *$ \\
\hline & & & $(0.12)$ & $(0.10)$ & $(0.04)$ & $(0.04)$ \\
\hline \multirow[t]{2}{*}{ FAI } & $-0.007 *$ & 0.001 & $-0.032 * * *$ & $-0.030 * * *$ & $-0.030 * * *$ & $-0.029 * * *$ \\
\hline & $(0.00)$ & $(0.00)$ & \begin{tabular}{|l|}
$(0.01)$ \\
\end{tabular} & $(0.01)$ & $(0.01)$ & $(0.01)$ \\
\hline \multirow[t]{2}{*}{ Manpower } & & & $1.613^{* * * *}$ & $0.492 *$ & $0.435^{* * * *}$ & $0.947 * * *$ \\
\hline & & & $(0.58)$ & $(0.25)$ & $(0.16)$ & $(0.27)$ \\
\hline \multirow[t]{2}{*}{ OFDI } & $-0.002 * * *$ & 0.0002 & 0.00500 & $0.002 *$ & 0.00200 & $0.005^{* *}$ \\
\hline & $(0.00)$ & $(0.00)$ & $(0.00)$ & $(0.00)$ & $(0.00)$ & $(0.00)$ \\
\hline \multirow[t]{2}{*}{ Economy } & $0.015^{* * *}$ & $0.013^{* * *}$ & $-0.035^{* * *}$ & $-0.018 * * *$ & $-0.017 * * *$ & $-0.031^{* * *}$ \\
\hline & $(0.00)$ & $(0.00)$ & $(0.01)$ & $(0.01)$ & $(0.00)$ & $(0.01)$ \\
\hline \multirow[t]{2}{*}{ Infrastructure } & $-11.803 * *$ & $-20.089 * * *$ & 27.82 & $38.823 * * *$ & $35.572 * * *$ & 34.72 \\
\hline & $(5.34)$ & $(6.23)$ & $(60.84)$ & $(10.13)$ & $(10.95)$ & $(40.93)$ \\
\hline \multirow[t]{2}{*}{ Industry } & -0.005 & -0.00400 & -0.0270 & 0.0280 & $0.029 *$ & 0.0540 \\
\hline & $(0.01)$ & $(0.01)$ & $\begin{array}{l}(0.04) \\
\end{array}$ & $(0.02)$ & $(0.02)$ & $\begin{array}{l}(0.03) \\
\end{array}$ \\
\hline area & Control & Control & Control & Control & Control & Control \\
\hline $\mathrm{AR}(1)$ & & & 0.001 & 0.004 & & \\
\hline $\mathrm{AR}(2)$ & & & 0.562 & 0.379 & & \\
\hline
\end{tabular}




\begin{tabular}{|c|c|c|c|c|c|c|}
\hline \multicolumn{7}{|c|}{ Table IV, cont } \\
\hline Hansen Test & & & 1.000 & 1.000 & & \\
\hline Difference-in-Hansen & & & 0.998 & 0.877 & & \\
\hline Observations & 620 & 572 & 510 & 542 & 542 & 542 \\
\hline R-squared & 0.8010 & 0.6402 & & & 0.402 & 0.275 \\
\hline Number of id & 31 & 31 & 30 & 31 & 31 & 31 \\
\hline
\end{tabular}

Note: Standard error is listed in brackets. The values of AR (1), AR (2) and Hansen Test and Difference-in-Hansen are p values.

\section{CONCLUSION AND COUNTERMEASURES}

Using the data of China's industrial capital and its total factor productivity from 1997 to 2016, and using panel VAR and mediating effect model, we find that: (1) Industrial transfer can significantly affect regional total factor productivity, and there is heterogeneity in the impact of industrial transfer and transfer-in area; (2) Industrial transfer promotes the total factor productivity of the industrial transfer-out area by promoting human capital, but there is no such path for the industrial transfer-out area.

The results show that labor-intensive, resource-intensive, high-energy-consumption and high-pollution enterprises in China may transfer industrial capital mainly based on the consideration of cost reduction, and do not realize the transformation from extensive economy to intensive economy. In addition, although the industrial capital is transferring to the central and western regions, the human capital has not changed significantly, which may be the main reason for the decline of the total factor productivity of the industrial transfer-in area. It indicates that the industrial transfer-in should not only absorb the industrial capital, but also pay attention to the industrial selection and human capital promotion, strengthen the infrastructure construction, promote the sustainable development of the transfer industry, so as to improve the quality of economic development.

\section{ACKNOWLEDGMENT}

About the author: Cangcang JIA (1994-), male, Han nationality, native of Xi'an, Shaanxi Province, master degree candidate, research direction is regional economy.

Contact address: Qingfeng Garden C, Chongqing Normal University, University Town, Shapingba District, Chongqing.

\section{REFERENCES}

[1] Xiusheng ZHANG, Xianhua HUANG. Does regional manufacturing industry transfer promote total factor productivity? --Research Based on the Data of Prefecture-level Cities in China [J]. Macro Quality Research, 2017, 5 (03): 62-75.

[2] Ming LU, Kuanhu XIANG. Solving the Conflict between Efficiency and Balance--On China's Regional Development Strategy [J]. Comparison of economic and social institutions, ,2014(04): 1-16.

[3] Caves R E. Multinational firms, competition, and productivity in host-country markets[J]. Economica, 1974, 41(162): 176-193.

[4] Wolff E, Blomström M. Multinational corporations and productivity convergence in Mexico $[\mathrm{M}] / /$ Convergence of productivity: Cross-national studies and historical evidence. Oxford University Press, 1994.

[5] Gongwei ZHANG, Xiang CHEN, Zan LI. FDI, Industrial Agglomeration and Total Factor Productivity Growth--An Empirical Analysis Based on Manufacturing Industry [J]. Scientific Research Management,2013,34(09): 114-122.

[6] Jianyong FAN, Meng FENG, Fangwen LI. Industrial Agglomeration and Total Factor Productivity [J]. World Economics;2014, 37 (05): 51-73.

[7] Yonghong MA, FAN Zhang, Xin SU. Research on The Path To Enhance The Technological Innovation Capability Of Enterprises In Less Developed Regions Based on the Perspective Of Interregional Industrial Transfer $[\mathrm{J}]$. Science \& Technology Progress and Countermeasures , 2015,32(21): 120-125.

[8] Ziyuan XIE, Lijuan WU. Industrial Agglomeration Level and Innovation Efficiency of Industrial Enterprises in China--An Empirical Study Based on Panel Data of 20 Industrial Industries from 2000 to 2012 [J]. Scientific Research Management,2017,38(S1): 91-99.

[9] Haddad M, Harrison A. Are there positive spillovers from direct foreign investment?: Evidence from panel data for Morocco[J]. Journal of development economics, 1993, 42(1): 51-74.

[10] Aitken B J, Harrison A E. Do domestic firms benefit from direct foreign investment? Evidence from Venezuela[J]. American economic review, 1999, 89(3): 605-618.

[11] Fanbin KONG, Zhengsong XU, Jun HU. Relationship between Economic Growth, Undertaking Industrial Transfer and Environmental Pollution--Empirical Study Based on Statistical Data of Jiangxi Province from 1989 to 2012 [J]. Economic Survey; 2017, 34 (02): 25-30.

[12] Liangwen CHEN. Economic Agglomeration Density and Labor Productivity Difference--An Empirical Study Based on Beijing Microdata [A]. Economics (Quarterly), Vol. 8, No. 1 [C]. : National Institute of Development, Peking University, 2008: 110-115. 